\title{
STAFF PROBLEMS OF INTERNATIONAL ORGANIZATIONS
}

T HE economic, social and political changes which have taken place throughout the world since 1945 have been responsible for setting a new pattern of international relationships completely different from those which existed before 1939. This has accounted for the rapid development of international work in all aspectseconomic, social, cultural, political and military-and in the creation of most of the familiar international organizations to-day. The international organization, working with a secretariat representative of all member countries, is thus a relatively recent phenomenon and has many unsolved problems.

International administration is still developing and largely experimental. It is only in the past few years that the basic problems of a multi-national organization have become apparent and that an effort has been made to study and understand them; it has been suggested that the future of international organizations will depend on their ability to remain flexible and avoid becoming set in their ways too soon. Unesco, for example, has acquired many new member states in the past few years, bringing its total membership to more than 100. This of necessity brings new problems of leadership and administration calling for a high degree of flexibility in policy and attitudes.

The most persistent problem with which the 'administration' of an international organization has to deal is that concerned with people and the maintenance of an efficient, loyal and contented staff of different nationalities with different cultures, different attitudes, different standards, and different methods of working. Much depends on the nature of the organization and its degree of independence and security. Both the European Coal and Steel Community and the International Bank operate with relative security and independence, since they do not rely on annual contributions from member states. The former is also guaranteed by a fifty-year treaty. This must greatly facilitate plans for the recruitment and training of staff and for the establishment of administrative practices and procedures. Again, good working relationships and clear lines of communication are relatively easy to establish in an agency such as the World Health Organization, where common professional interests override national and cultural differences and help to unite the working group. Other organizations with highly diversified programmes requiring experts in widely differing fields find that this tends to divide rather than unite the group. Leadership and morale then become of supreme importance.

There is still, fortunately, much enthusiasm and high idealism associated with international work and there are many sources of satiafaction for the individual, but the nature of its organization and the administrative techniques used bring difficulties and frustrations which have no counterpart elsewhere. The question of morale is always a difficult one, but is particularly complicated in the international group, where the necessity of being truly representative can sometimes override all other considerations, and where the problem of 'communications' is unusually difficult. It is paradoxical that the international organization must be representative if it is to be efficient. This, of itself, complicates the normal procedures associated with the administration of personnel and the techniques used in the personnel management function.

These problems and the way in which they have been tackled have been described by Mrs. V. M. Clarke in an article entitled "The International Organization", which is published in the December issue of Personnel Management $(45,154 ; 1963)$.

\section{PRESTRESSED CONCRETE}

$\mathrm{P}^{\mathrm{R}}$ RESTRESSED concrete, already well established in the field of civil engineering, is now becoming an increasingly used structural material in the design of modern buildings, but its potentialities in this respect have not yet been sufficiently realized. This is the view expressed by the Prestressed Concrete Development Group in a recent illustrated pamphlet entitled The Use of Prestressed Concrete in Buildings*, published by the Cement and Concrete Association, 52 Grosvenor Gardens, London, S.W.1, January 1964.

As a structural material, concrete is very strong in compression but weak in tension, and the basic principle behind prestressed concrete is to eliminate such weakness. The technique is to apply compressive stresses with high tensile steel tendons to those parts of a concrete member normally in tension (the bottom of a beam, for example), thus making those parts also in compression, resulting in extremely strong concrete units. Two methods of prestressing concrete are used, one known as 'pre-tensioning', the other as 'post-tensioning'. The former is normally used in factory production and depends largely on achieving complete bond between tendons and concrete, very much as is the case with reinforced concrete. "The tendons are first stressed in the forms, and anchored at their ends. Concrete is then placed around the tendons * Prestressed Concrete Development Group. The Use of Prestressed Con-
crete in Buildings. Pp. 16. (London: Prestressed Concrete Development crete in Building which are released from their anchorages when the concrete has reached the required strength. The member is now under compression." Post-tensioning is the process largely used for concrete in situ and is particularly suitable for large structural members. In this process the concrete is emplaced around ducts enclosing the tendons, preventing them from bonding to the concrete. After hardening and reaching the required strength, the tendons are stretched by hydraulic jack and anchored at the ends of the member, placing it in compression. The ducts are grouted solid; this prevents corrosion of the tendons and improves the losd-bearing properties of the concrete member. An alternative method is to form the duct of solid rubber, inflatable rubber tubing, or some other easily extractable material; in this case the material is withdrawn some twelve hours after concreting and the tendons placed in the duct so formed.

From a practical point of view, prestressed concrete in buildings permits of large spars with relatively shallowsectioned members, even where heavy loads are envisaged. This means fewer columns, more unrestricted floor space, equally a reduction in weight and floor-to-floor heights. Where tall buildings and deep basements are involved, the prestressed concrete retaining wall can be used for reducing wall thickness. It is claimed that resthetically the appearance of a building may be much improved by prestressed concrete in affording opportunities for designing large uninterrupted spans, sweeping shell canopies 
and cantilevers. Economically, prestressing means a saving in materials; this can be set against the extra cost incurred in factory or site production. Emphasis is rightly laid on the paramount necessity of the fullest co-operation between architect, engineer and contractor if full advantage is to be taken of prestressed concrete in buildings.

The advent of the Ml motorway, perhaps more than any other highway development in Britain since the end of the Second World War, impressed on the general public the fact that the art of concrete bridge design had not only come to stay but was potentially capable of rapidly increasing development in modern eivil engineering projects. In point of fact, concrete, and particularly prestressed concrete, has since become the almost universally favoured constructional material for bridges in Britain, as in the United States, Europe and elsewhere. From 1950 onwards, many highway bridges were constructed in prestressed concrete, but almost every design depended on the particular local problem with which the engineer was at the time concerned. Consequently, a large variety of prestressed beam sections was devised, each requiring a special formwork, much of this without any attempt at standardization.

Manufacturers found that when some form of standardization was tried for their beam section products, as proprietary units, dependence on such beams in certain cirumstances conflicted with the requirements of local authorities and the Ministry of Transport when it aame to competitive tendering for contracts. The economic and practical advantages stemming from some form of standardization of precast concrete beam sections for bridges for specific open ranges, acceptable slike to the Ministry, local authorities and products manufacturers, soon became the terms of reference of the Prestressed Concrete Development Group which pioneered the publication Standard Beam Sections for Prestressed Concrete Bridges: (1) Inverted T Beams for Spans from 25 to $55 \mathrm{ft}$. (Second edition. London: Cement and Concrete Association, October 1963).

In the range of spans from 40 to $85 \mathrm{ft}$., the most frequently used sections are either hollow box or composite $T$ sections, and in this connexion a further booklet, Pc. 4, Standard Beam Sections for Prestressed Concrete Bridges: (2) Box Section Beams for Spans from 40 to $85 \mathrm{ft}$. has been published by the Groupt. Concerning these particular spans, ". . experience has shown that an economical solution can be provided either by a bridge deck com. prising bearns of hollow box section placed side by side with narrow in situ joints between, or by one in which beams of precast I section, more widely spaced, are made composite with an in situ slab on top, and thus act as T beams". This booklet (Pc. 4) gives details of recommended box section units; it also includes examples of typical analyses of bridges using the standard sections.

It is intended that the I sections for composite T-beam bridges will be described in a later booklet. It is also predicted that standard sections may be extended in future to spans exceeding $85 \mathrm{ft}$.; such sections, however, would probably have to be post-tensioned owing to the Ministry's present edict prohibiting transport by road of loads more than $90 \mathrm{ft}$. long.

† Prestressed Concrete Development Group. Standard Beam Sections for Prestressed Bridges-(2) Box Section Beams for Spans from 40 to $85 \mathrm{ft}$. $\mathrm{Pp}$. 16. (London: Prestressed Concrete Development Group, 1964.)

\section{THE LABORATORY ANIMAL SCIENCE ASSOCIATION}

$\mathrm{R}$ ECENT developments in such widely differing spheres as chemotherapy, nutrition, toxicology and virology have led to changes in the role of experimental animals in research. A more general awareness is developing in the basic biological disciplines that projects involving experimental animals are more likely to be brought to a successful conclusion if the animals themselves are healthy and are accorded proper care. The production of healthy animals has in itself led to a new field of research, utilizing techniques to control their bacterial flora and eliminate unwanted parasites. The cost of animals and providing for their maintenance during experimentation is far from negligible, and efficiency both of production and usage is a goal to be attained.

Those whose scientific interest is in this sphere are from a variety of disciplines, and it is to be regretted that at this time there is no formal training in the scientific aspects of laboratory animal care available in the United Kingdom.

For the past seventeen years, the Laboratory Animals Centre (formerly Bureau) of the Medical Research Council has acted as an agency for the dissemination of information and advice on laboratory animals, a task which it has performed with notable success. The present director of the Centre, Dr. Lane-Petter, has been responsible for the organization of an annual symposium dealing with some broad aspects of laboratory animal science. The large attendances at these meetings were, in themselves, evidence of the keen interest shown by research workers to improve their knowledge of the proper care and use of laboratory animals.

The success of these meetings prompted scientists in both academic and industrial institutions to hold discussions with representatives of the Laboratory Animals Centre, the Universities Federation for Animal Welfare and the Animal Technicians Association concerning the formation of an essentially graduate organization interested in all aspects of laboratory animal science.
These discussions led to the formation of the Laboratory Animal Science Association in November 1963. Among the objectives of the new Association are the exchange of information between scientists and others concerned with the production, use and care of experimental animals and the stimulation of educational bodies, particularly the universities, to provide undergraduate and postgraduate training in laboratory animal science. It also seeks to co-operate with other organizations interested in the promotion of the highest standard of animal care throughout Britain.

It is intended to hold symposia and lectures and to arrange meetings for the presentation and discussion of papers by members. It is also hoped to organize visits to laboratories and breeding units for demonstrations of equipment and techniques.

Dr. Lane-Petter has made available the annual Laboratory Animals Centre Symposium and the associated Collected Papers as the basis for future meetings and publications. The first symposium of the new Association will be held on May 20 at the Royal Society of Medicine, 1 Wimpole Street, London, W.1. The topies to be discussed include: the significance of organ weights in toxicity testing (Dr. L. Golberg); factors affecting the growth rate of laboratory animals (Dr. E. Widdowson); and the use of laboratory animals in experimental hæma. tology (Dr. E. V. Hulse).

The first publication of the Association (Laboratory Animal Science) will include papers selected from those presented to the NATO Advanced Study Institute on Experimental Animals in Research held at Harrogate during September 9-20, 1963 (Nature, 201, 354; 1964).

Further information concerning the Laboratory Animal Science Association can be obtained from the honorary secretary, Dr. D. E. Stevenson, Tunstall Laboratory, 'Shell' Research, Ltd., Sittingbourne, Kent. 